\title{
Online oxygen monitoring using integrated inkjet-printed sensors in a Liver-On- a-Chip system
}

\author{
A. Moya, ${ }^{a, e}$ M. Ortega-Ribera, ${ }^{b}$ Xavier Guimerà, ${ }^{c}$ E. Sowade, ${ }^{d}$ M. Zea, ${ }^{a}$ X. Illa, ${ }^{a, e}$ E. Ramon, ${ }^{a}$ \\ R. Villa, ${ }^{a, e}$ J. Gracia-Sancho, ${ }^{\text {b,f }}$ G. Gabriel*,a,e
}

The demand for real-time monitoring of cell functions and cell conditions has dramatically increased with the emergence of Organ-On-a-Chip (OOC) systems. However, the incorporation of co-cultures and microfluidic channels in OOC systems increases their biological complexity and therefore makes the analysis and monitoring of analytical parameters inside the device more difficult. In this work, we present an approach to integrate multiple sensors in an extremely thin, porous and delicate membrane inside a Liver-On-a-Chip device. Specifically, three electrochemical dissolved oxygen (DO) sensors were inkjet-printed along the microfluidic channel allowing local online monitoring of oxygen concentrations. This approach demonstrates the existence of an oxygen gradient up to $17.5 \%$ for rat hepatocytes and $32.5 \%$ for human hepatocytes along the bottom channel. Such gradients are considered crucial for the appearance of zonation of the liver. Inkjet printing (IJP) was the selected technology as it allows drop on demand material deposition compatible with delicate substrates, as used in this study, which cannot withstand temperatures higher than $130{ }^{\circ} \mathrm{C}$. For the deposition of uniform gold and silver conductive inks on the porous membrane, a primer layer using SU-8 dielectric material was used to seal the porosity of the membrane at defined areas, with the aim of building a uniform sensor device. As a proof-ofconcept, experiments with cell cultures of primary human and rat hepatocytes were performed, and oxygen consumption rate was stimulated with carbonyl-cyanide-4-(trifluoromethoxy)phenylhydrazone (FCCP), accelerating the basal respiration of $0.23 \pm 0.07 \mathrm{nmol} / \mathrm{s} / 10^{6}$ cells up to $5.95 \pm 0.67 \mathrm{nmol} / \mathrm{s} / 10^{6}$ cells s for rat cells and the basal respiration of $0.17 \pm 0.10 \mathrm{nmol} / \mathrm{s} / 10^{6}$ cells by up to $10.62 \pm 1.15 \mathrm{nmol} / \mathrm{s} / 10^{6}$ cells for human cells, with higher oxygen consumption of the cells seeded at the outflow zone. These results demonstrate that the approach of printing sensors inside an OOC has tremendous potential because IJP is a feasible technique for the integration of different sensors for evaluating metabolic activity of cells, and overcomes one of the major challenges still remaining on how to tap the full potential of OOC systems.

\section{Introduction}

Over the past two decades, multidisciplinary efforts in cell biology and bioengineering have led to highly functional invitro cell culture platforms enabling the depiction of microenvironmental signals. ${ }^{1}$ The purpose of in-vitro culture platforms is to model reality with the highest possible attention to detail in order to mimic human and other animal pathophysiology. As a result, cell biology systems are moving from conventional in-vitro models ${ }^{2}$ to more complex systems, which are better able to capture the critical features of cellular microenvironments. ${ }^{3}$ In this context, the concept of 'OrganOn-a-Chip' (OOC) has emerged. ${ }^{4-6}$ Micro-engineering strategies, such as microfabrication and microfluidic technologies provide a number of unique advantages and benefits in the study of organ biology. ${ }^{7}$ An OOC system consists of a microfluidic cell culture device that contains continuously perfused chambers inhabited by living cells arranged to simulate tissue- and organ-level physiology. ${ }^{8,9}$ The main advantage of these miniaturized organ models over conventional models ${ }^{2}$ is that they can more accurately predict human responses because they are able to capture the structural, mechanical, chemical, and communicative complexities on in-vivo systems. ${ }^{3}$ For this reason, in some areas of cell biology, OOC systems could be an effective alternative to animal testing as the process of testing drugs with animals often fails to predict human pathophysiology..$^{10,11}$
The ability to monitor cell culture conditions and their response to drugs or other stimulations allows continuous improvement of the models. Currently, analysis of OOC cell cultures mainly relies on conventional tools such as optical measurement techniques using time-lapse bright field and fluorescence microscopy ${ }^{12}$ in combination with various staining techniques as well as collection of supernatants and cellular samples. ${ }^{13}$ However, these traditional techniques are problematic because they are time-consuming, require manual sample collection from the microfluidic system, need large working volumes, and are subject to system disturbance, making them unsuitable for miniaturized cell culture systems. Consequently, over the past few decades, a great deal of research has been carried out in the development of sensors for cell biology applications and of particular interest has been the development of miniaturized sensors with improved sensitivities and limits of detection. ${ }^{14,15}$

Recently, a number of review articles have advocated the integration of functional tools for cell monitoring within $\mathrm{OOC}$ systems ${ }^{16-21}$ which has led to a strong demand for the integration of online sensor capabilities. Some studies have incorporated high-cost commercial microsensors; ${ }^{22}$ however, only few research works have described the integration of minimal invasive sensors in $O O C$ devices. This can be easily understood because conventional manufacturing processes do not allow for the direct integration of sensors in OOC systems, due to complex, ${ }^{22,23}$ multi-step fabrication processes, high temperature requirements or material incompatibility, which increase the complexity of the whole system and the overall 
probability of failure. ${ }^{24}$ However, in the last few years, various strategies have been proposed for real-time monitoring without compromising the operation of the OOC. Some works have focussed on the monitoring of the physical parameters external to the cell culture area of the OOC, using modular sensing platforms ${ }^{23,25-27}$ in-line with the microfluidic system to measure the inlets and outlets without disturbing the cell culture area. Recently, Zhang et al. $^{23}$ presented a fully integrated multi-sensing platform to achieve automated in-situ monitoring of biophysical ( $\mathrm{pH}$, oxygen, temperature) and biochemical parameters of a liver- and heart-on-a-chip model systems. Other strategies have gone a step further by placing a monitoring device inside the OOC. In this regard, some studies have incorporated external probes modifying the bioreactor design, ${ }^{22,28,29}$ others have integrated sensors inside the cell culture area, in the top and or bottom covers of the device without disturbing its functionality. ${ }^{30}$ Curto et al. ${ }^{31}$ presented the coupling of organic electrochemical transistors with microfluidics to achieve multi-parametric (optical imaging, impedance monitoring, and metabolite sensing) monitoring of live kidney cells. These sensing elements were placed at the glass bottom cover of the system using conventional microtechnology techniques, in clean room environments using a complex, multi-step lithography process. Henry et al. ${ }^{32}$ reported embedded electrodes for trans-epithelial electrical resistance (TEER) measurements, patterned onto the polycarbonate substrate forming the top and bottom covers on an OOC system. The same system has been reported with the integration of both TEER and multi-electrode arrays sensors. ${ }^{33}$ More recently, Lind et al. ${ }^{34}$ presented a new approach to integrate strain gauge sensors inside a cell incubator environment, fully based on three-dimensional printing techniques for a continuous electronic readout of contractile stress of cardiac micro-tissues.

Among all the necessary parameters to be monitored inside an OOC system, the amount of oxygen is one of the most important. Oxygen is an important regulatory parameter, influencing cell differentiation and function. ${ }^{19}$ In addition, cellular function and behaviour are affected by oxygen tension in micro-enviroments. ${ }^{20}$ For this reason, changes in oxygen tension, either above physiological oxygen tension (hyperoxia) or below physiological levels (hypoxia) or even a complete absence of oxygen (anoxia), can trigger potent biological responses and therefore need to be controlled precisely. With improvements in the microfabrication technology field, the miniaturization of oxygen sensors has dramatically increased. This advance has allowed an easier integration of oxygen sensors principally of microfluidic systems for in-situ measurements. ${ }^{20,35}$ Some researchers have designed their own oxygen sensors incorporating them in bioreactors; ${ }^{25,36,37}$ others, have modified the system in order to incorporate commercial oxygen probes. ${ }^{22,29,38}$ However, the incorporation of co-cultures and several microfluidic channels separated by membranes inside OOC systems has made them more complex and hindered the integration of sensors. The challenge therefore is how to integrate sensors inside their own channels and embed them in the cell culture membrane without damaging its filtering function.
In this research study, we present for the first time, to the best of our knowledge, the integration of amperometric oxygen sensors in an ultrathin and porous cell culture membrane of a Liver-On-a-Chip system to achieve in-situ, simultaneous and real-time monitoring of oxygen along the cell culture microfluidic chamber. Oxygen availability is particularly important in the field of liver pathophysiology, because the oxygen gradient is considered crucial for the appearance of zonation of metabolism in the liver microarchitecture. ${ }^{39}$ Zonation is critical for achieving accurate models of in-vivo function, and because several transformations occur in the different sinusoidal zones affecting hepatotoxicity, the monitoring of oxygen is crucial. To overcome this technological challenge, we fabricated oxygen sensors by Inkjet Printing (IJP). IJP is a promising, low-cost printing technique alternative to conventional microelectronic fabrication, which allows the integration of electrodes in a wide range of substrates compatible with low temperature processes. IJP technology has recently been used to integrate electrodes in cell culture devices, ${ }^{40}$ microfluidic systems ${ }^{41}$ and even for the development of parts of microfluidic channels. ${ }^{42}$ In IJP, droplets of liquids are ejected from a small nozzle. There is no direct contact between the print head and the substrate. In addition, no mask is required for the process, since the droplets are transferred directly to the substrate. This direct writing approach without the need of masks drastically reduces overall fabrication time and the cost of the sensors, and facilitates iterative design changes during sensor development.

In this work, three electrochemical dissolved oxygen (DO) sensors were situated in the porous membrane of a specific Liver-On-a-Chip device, named ExoLiver, ${ }^{43}$ which mimics the liver sinusoid. The ExoLiver is a modular bioreactor consisting of two plates separated by a porous membrane, with an upper microfluidic channel and a static lower channel where hepatocyte cells are cultivated. Inkjet-printed sensors were integrated along the microfluidic channel, specifically in the bottom part of the membrane monitoring oxygen concentration changes in order to give real-time information about the state of the cell culture, to evaluate if an oxygen gradient exists along the hepatocytes cell culture and to enable the study of the oxygen consumption rate (OCR) of the cells under different conditions. The location of the electrodes embedded in the membrane is important as the main oxygen changes are observed in the immediate vicinity of the cell culture due to low cultivation volumes and unaltered functionality of the system. The incorporation of an array of sensors embedded in the membrane, which has not been reported to date, may provide more realistic measurements of oxygen changes for evaluating metabolic activity rather than general DO values, for example at external inlets or outlet ports. The principle of IJP fabrication approach and the morphological and functional characterization of the DO sensors on plastic substrate have already been demonstrated in our previous work. ${ }^{44}$ However, here the challenge is to integrate the sensors in a very thin $(65 \mu \mathrm{m})$ and porous membrane, using the concept of a printed primer layer to 
partially seal the membrane porosity allowing the deposition of smooth layers on top of it.

Biological proof of concept of these sensors was performed using primary human and rat hepatocytes cultured in the lower plate of the ExoLiver bioreactor. DO concentrations were monitored in real-time for several hours and changes in culture media were induced with Carbonyl-cyanide-4(trifluoromethoxy)phenylhydrazone (FCCP), a mitochondrial oxidative phosphorylation uncoupler that disrupts ATP synthesis by transporting protons across cell membranes. ${ }^{45,46}$ Because FCCP depolarizes mitochondrial membrane potential, it promotes an increase in hepatocyte respiration and hence in oxygen consumption, increasing the effect of the oxygen gradient in the vicinity of the hepatocyte cells from the inflow (periportal-like) to the outflow (perivenous-like) zones. The experimental results show that the proposed manufacturing approach involving the printing of sensors located next to the cells allows online oxygen measurements, offering a technological solution to better control cell metabolites, with the study of the oxygen gradient and the cells respiration rate along the bioreactor. This approach also bridges an existing gap regarding the integration of monitoring tools within perfused $O O C$ systems. We clearly demonstrate the feasibility of readily embedding sensors in the porous membrane of an OOC system, which represents the first step toward a truly integrated $\mathrm{OOC}$ system. Such a devise will enable investigation of different biological parameters and thereby improve the predictive quality of the data used to inform clinical studies.

\section{Experimental}

\section{Materials and equipment}

Three commercially available ink formulations were used for printing the DO sensors. A low-curing gold nanoparticle ink formulation (Au-LT-20 from Fraunhofer IKTS, Germany), a silver nanoparticle ink (DGP-40LT-15C from ANP, Korea) and a dielectric photoresist SU-8 (SU-8 2002 from MicroChem, USA). All the ink formulations were printed with a drop-on-demand Dimatix Materials Printer (DMP 2831 from Fujifilm Dimatix, USA). Microporous polytetrafluoroethylene (PTFE) membrane filters (JGWP04700 from Milipore, USA) were employed as substrates. The membrane was $65 \mu \mathrm{m}$ thick and had a $0.2 \mu \mathrm{m}$ pore size with $80 \%$ of porosity and had undergone a special chemical treatment to convert the hydrophobic PTFE into hydrophilic. Ethanol (LC/MS grade), sodium nitrate $\left(\mathrm{KNO}_{3}\right)$, potassium hexacyanoferrate(III) $\left(\mathrm{K}_{3}\left[\mathrm{Fe}(\mathrm{CN})_{6}\right]\right)$ and potassium hexacyanoferrate(II) trihydrate $\left(\mathrm{K}_{4}\left[\mathrm{Fe}(\mathrm{CN})_{6}\right]\right)$ and hydrochloric acid $(0.1 \mathrm{M}$ ) (all from Sigma Aldrich, Spain) were used for the preparation and characterization of the printed sensors. The electrochemical characterization of the sensors and the experimental procedure were performed with an 8-channel potentiostat $1030 \mathrm{~B}$ Electrochemical Analyzer ( $\mathrm{CH}$ Instruments, USA). A Clark-type commercial microelectrode (OX-NP, Unisense, Denmark) with a top diameter of $25 \mu \mathrm{m}$ was used to correlate the DO printed sensor measurements with a 4channel amplifier microsensor multimeter (Unisense, Denmark).
Scanning Electron Microscopy (SEM, Auriga-40 from Carl Zeiss) was performed to analyse the surface structure of the porous PTFE membrane and to study the morphology of each printed layer.

Hepatocytes were isolated using Collagenase A (103586, Roche), $\mathrm{CaCl}_{2}$ (C3306, Sigma) and Hepes (H3375, Sigma) all dissolved in Hanks Balanced Solution salt (HBSS; H8264, Sigma). Dulbecco's Modified Eagle's Medium (DMEMF12; 11320074 , Gibco) was the selected culture media for primary hepatocyte supplemented with $2 \%$ Fetal Bovine Serum (FBS; 04-001-1A, Reactiva), 1\% penicillin plus $1 \%$ streptomycin (03331-1C, Reactiva), 2 mM L-glutamine (25030-024, Gibco), 1\% amphotericin B (03-029-1C, Reactiva), $1 \mu \mathrm{M}$ dexamethasone (D4902, Sigma), Dextran (31392, Sigma) and $1 \mu \mathrm{M}$ insulin (103755, HCB). Hepatocytes were cultured on Poly methyl methacrylate (PMMA) plates previously treated with plasma (BD-10AV, Electro-technic products) and coated with 0.1 $\mathrm{mg} \cdot \mathrm{mL}^{-1}$ collagen type 1 rat tail (A10483-01, GIBCO).

For the experimental procedure, cells were washed with Dulbecco's phosphate-buffered saline (DPBS; 02-023-1A, Reactiva). Indirect dynamic stimulation of the cell culture was performed through the perfusion system of the device connected to a peristaltic pump (HV707000-HARVARD peristaltic pump P70). FCCP (370-86-5, Cayman Chemical) was used to increase the oxygen consumption of the hepatocytes.

\section{Inkjet printing process}

A primer layer was printed on the membrane in order to selectively seal the porosity where the sensors were placed. The strategy to print a primer layer with IJP has been previously demonstrated for paper-based substrates. ${ }^{47,48}$ However, in this study, we faced the challenge of applying the same strategy but in a $65 \mu \mathrm{m}$ thick substrate with a porosity $80 \%$.

Fig. 1a shows the manufacturing steps of the DO sensors. The first printing step was the primer layer using SU-8 ink (Fig. $1 a(i))$ locally sealing only the area under the electrodes. Two SU-8 layers were printed using a wet-on-wet method with a spacing between drops (DS) of $15 \mu \mathrm{m}$ at a print resolution of 1693 dpi (dots per inch). This DS provided overlap as each drop spread. The SU-8 was cured by UV during $15 \mathrm{~s}$ to polymerize the layer by cross-linking. Gold elements (working electrode (WE) and counter electrode (CE)) were then printed also using a DS of $15 \mu \mathrm{m}$ between each pixel (Fig. 1a(ii)). Platen temperature was set to $40^{\circ} \mathrm{C}$ in order to evaporate the solvent during the printing process and to improve layer homogeneity. The next step was printing the silver elements for the development of the electrode structures that form the pseudo-reference electrode (pRE) using a DS of $30 \mu \mathrm{m}(846$ dpi) (Fig. 1a(iii)). Both printed inks were then thermally dried at $100{ }^{\circ} \mathrm{C}$ for $5 \mathrm{~min}$ and then sintered on a hotplate at $130{ }^{\circ} \mathrm{C}$ for $40 \mathrm{~min}$. The sintering temperature was selected as it is the maximum temperature that the PTFE membrane can withstand without destroying its hydrophilic treatment. With these sintering conditions, the sheet resistance of both metallic inks was lower than $2 \Omega \cdot \square^{-1}$, as shown in Fig. S1 (ESI+). Afterwards, in order to precisely define the active area of the 
electrodes and the pad connections, dielectric SU-8 was printed over the sintered layers. An oxygen plasma treatment was applied before the printing of the dielectric in order to change the surface energy of the printed layers and to increase their hydrophilicity (Fig. 1a(iv)). A DS of $15 \mu \mathrm{m}$ (1693 dpi) was selected to print the dielectric which was then cured using a UV lamp for $15 \mathrm{~s}$. A more detailed description of the sensor fabrication in the membrane is shown in Fig. S2 (ESIt). Fig. 1b shows two images of the membrane with the three printed DO sensors, showing the high flexibility of the PTFE membrane substrate. An o-ring elastomer was positioned to define the cell culture area of $34 \times 28.5 \mathrm{~mm}^{2}$, and to seal the bioreactor, as shown in Fig. $1 \mathrm{~b}$ (right).

Finally, two electrochemical steps were required to obtain functional sensors. Firstly, the printed silver electrode was chlorinated by cyclic voltammetry in $0.1 \mathrm{M} \mathrm{HCl}$, scanning the potential from $0 \mathrm{~V}$ to $0.2 \mathrm{~V}$ versus the $\mathrm{Ag} / \mathrm{AgCl}$ commercial reference electrode at $20 \mathrm{mV} \cdot \mathrm{s}^{-1}$ to obtain a stable pRE. Secondly, the gold WE surface was electrochemically activated

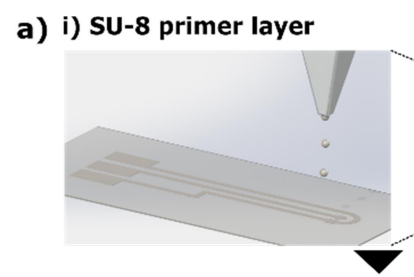

\section{Cross-section}

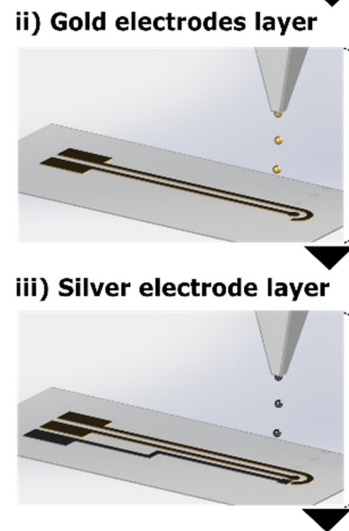

iv) SU-8 passivation layer
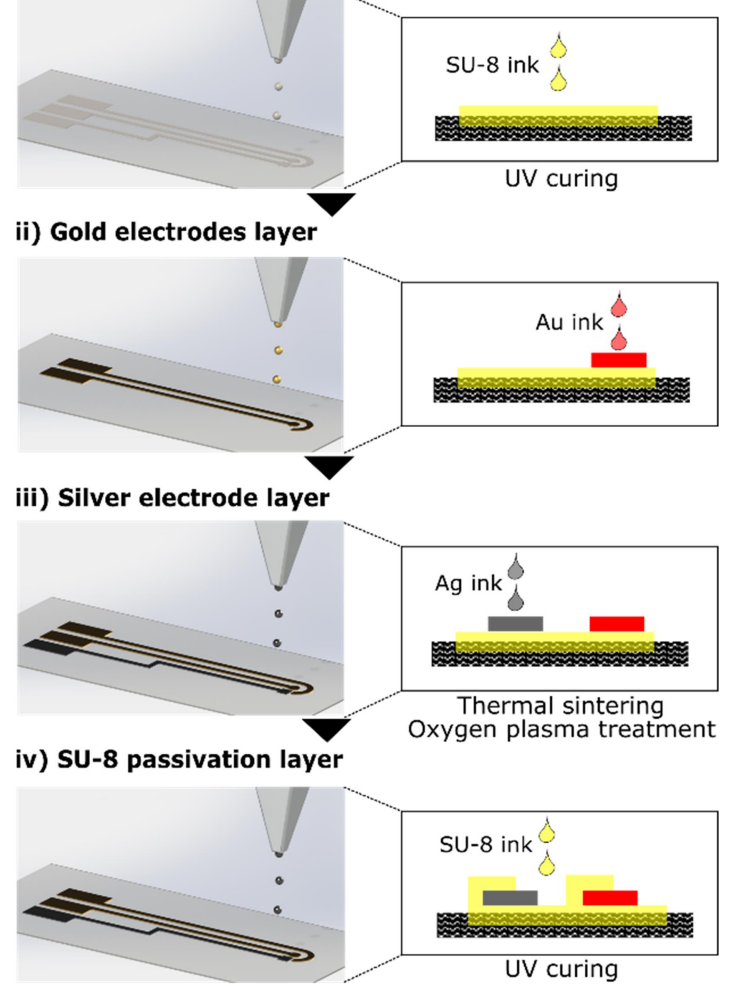

b)
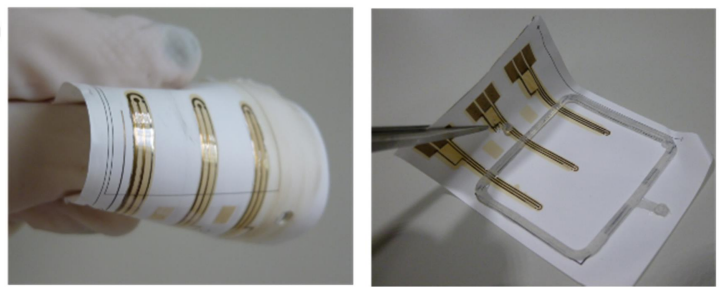

Fig. 1 a) Fabrication steps of the DO sensor based on IJP with printing of the primer layer, printing of the gold and silver elements and printing of the passivation layer after thermal sintering and plasma treatment, b) photographs of the final DO sensors with the attached silicon o-ring on the porous flexible membrane. in order to enhance its electron transfer kinetics. ${ }^{50}$ The behavior of the gold electrode in many electrolytes is influenced by the character of the gold surface. The aim of this activation process was to clean and form a uniform atomic structure in the metallic electrode surface by desorbing impurities and eliminating any native oxide. ${ }^{51}$ The best activation conditions found were 2 pulses alternating between - $2 \mathrm{~V}$ and $0 \mathrm{~V}$ for $5 \mathrm{~s}$ in a PBS electrolyte solution.

\section{Cell culture procedure}

For the biological validation of the sensors within the $\mathrm{OOC}$ device, primary hepatocytes were isolated from male Wistar Han rats (Charles River Laboratories Barcelona, Spain) weighing 300-350 g housed at the University of Barcelona (UB) animal facilities or from remnant peritumoral tissue obtained after partial hepatectomy in humans. Biocompatibility tests were performed for the inks by culturing hepatocytes onto a membrane with printed patterns of the three different used inks. Fig. S4 $(E S I t)$ shows that the cells achieved their morphological properties by maintaining their viability, as is also the case for membranes without sensors.

All experiments were approved by the Laboratory Animal Care and Use Committee of the University of Barcelona and were conducted in accordance with the European Community guidelines for the protection of animals used for experimental and other scientific purposes (European Economic Community (EEC) Directive 86/609). Regarding human tissue, the Ethics Committee of the Hospital Clínic de Barcelona approved the experimental protocol ( $\mathrm{HCB} / 2015 / 0624)$ and in all cases patients received and agreed informed consent.

Hepatocytes were isolated as previously described $\mathrm{in}^{52}$. Briefly, liver tissue was rinsed and digested with $0.015 \%$ collagenase A in Hank's containing $12 \mathrm{mM}$ hepes ( $\mathrm{pH} 7.4)$ and $4 \mathrm{mM} \mathrm{CaCl} 2$ for $10 \mathrm{~min}$ at $37^{\circ} \mathrm{C}$. Disaggregated tissue was filtered using a $100 \mu \mathrm{m}$ nylon strainer, collected in cold Krebs' buffer and centrifuged at $50 \mathrm{~g}$ for $5 \mathrm{~min}$. Pellets containing hepatocytes were rinsed three times with HBSS. Hepatocytes above $80 \%$ viability (evaluated by trypan blue exclusion) and were cultured in PMMA platforms (previously treated with oxygen plasma and collagen type 1 coating) with enriched culture media and maintained $\mathrm{O} / \mathrm{N}$ at $37{ }^{\circ} \mathrm{C}$ in a humidified atmosphere of $5 \% \mathrm{CO}_{2}$. Cells were seeded at a density of 109.000 cells $/ \mathrm{cm}^{2}$. After isolation for $16 \mathrm{~h}$, hepatocytes were rinsed twice with DPBS and media was changed to DMEMF12 supplemented with $2.97 \%$ dextran to simulate blood viscosity.

\section{Oxygen monitoring experimental procedure}

Prior to embedding the inkjet-printed sensors in the membrane, calibration of the sensor platform was performed as it is described in the section 'Experimental procedure' $(E S I)$. Fig. S3 $(E S I+)$ shows the setup of the experimental procedure.

DO was recorded in real-time and simultaneously every 15 $\min$ in the three points of the bioreactor lower channel where the inkjet-printed sensors were placed. A commercial Clarktype sensor was set to obtain measurements every second at a single point on the upper channel. After $3 \mathrm{~h}$ of culture 
stabilization, the increase in oxygen consumption from hepatocytes was induced by adding FCCP $(0.5 \mu \mathrm{M}$ steps) to the culture reservoir. After the first addition, the system was set under anaerobic conditions by closing the medium reservoir to avoid oxygenation. Real-time oxygen assessment was performed for up to $5 \mathrm{~h}$ after drug administration to the cell culture. Control experiments without cells were also performed. $\mathrm{N}=3$ independent cell isolations and experiments were performed for both rat and human hepatocytes.

\section{Results and discussion}

\section{Strategy of blocking the porous membrane with SU-8}

Thanks to advances in technology, it is now possible to integrate sensing elements in ultrathin and porous cell culture membrane using IJP techniques. However, conductive inks cannot be printed directly onto the porous membrane (Fig. 2a) as this would cause short circuits and a non-defined electrode area. To electrically isolate the sensors from the microfluidic medium, the porosity of the membrane was sealed using a primer layer (Fig. 2b). The primer layer was locally printed just under the electrodes area blocking the minimal area, in order to not affect the diffusion inside the membrane. With this strategy, a smooth and non-porous surface of conductive materials can be obtained after the printing of the primer layer (Fig. 2c). SU-8 was selected because as it is an UV curable ink formulation, it forms quite thick layers compared with standard solvent-based ink formulations, allows the efficient sealing of the porous membrane and due to its biocompatibility with cell culture systems. ${ }^{49}$ Different numbers of SU-8 layers were printed and tested (non-primer (OL), one (1L), two (2L), three (3L) and four layers (4L)). Fig. $2 b(\mathrm{i}-\mathrm{iv})$ shows the sealing of a $10 \mu \mathrm{L}$ volume water drop on top of various primer layers. Additionally, Fig. $2 b$ (v-viii) shows the cross section of the membrane showing the SU-8 penetration for the different number of layers applied. In the case of $1 \mathrm{~L}$, the water droplet was completely absorbed by the porous membrane and did not form a sessile droplet on top (Fig. $2 b(i))$. In this case it is very difficult to observe the SU- 8 in the membrane (Fig. $2 b(v)$ ), the SU- 8 covered the fibres of the membrane without sealing its porosity, just a thin layer of SU-8 at a penetration depth of about $2.4 \pm 1 \mu \mathrm{m}$ can be identified Fig. $2 b$ (ix) shows the measured primer layer thicknesses for the different number of layers, taking into account the SU-8 ink that was penetrated inside the membrane and also the material that was overflowing above the membrane. In the case of $2 \mathrm{~L}$, the porosity of the membrane was already blocked and the drop water test remained on the sealed membrane surface (Fig. $2 \mathrm{~b}(\mathrm{ii})$ ). The SU-8 had a penetration depth of about $16.8 \mu \mathrm{m} \pm 3 \mu \mathrm{m}$ as shown in Fig. $2 \mathrm{~b}(\mathrm{vi})$. In the case of $3 \mathrm{~L}$ and $4 \mathrm{~L}$ it can be considered that the polymer was completely blocking the membrane. In these cases, the SU- 8 had already formed a thin layer overflowing above the membrane. In the case of $3 \mathrm{~L}$, the ink penetration depth in the membrane was about $28.5 \pm 4$ $\mu \mathrm{m}$ and the layer thickness on top of the membrane about 6.9 $\pm 3 \mu \mathrm{m}$ (Fig. $2 \mathrm{~b}$ (vii)). For the $4 \mathrm{~L}$ the penetration depth of $\mathrm{SU}-8$ was about $31.2 \pm 5 \mu \mathrm{m}$ and the SU-8 formed a smooth layer on top of the membrane of about $20.7 \pm 5 \mu \mathrm{m}$ (Fig. $2 \mathrm{~b}$ (viii)).

\section{Printing of the conductive inks onto the primer layer}

The printing behaviour of gold and silver inks on top of the primer layer deposited on the porous membrane was studied. One layer of the conductive inks was printed in patterns of $4 x$ $4 \mathrm{~mm}^{2}$ over a SU-8 pattern of $5 \times 5 \mathrm{~mm}^{2}$ for the different number of primer layers, as shown in Fig. S5 (ESI+). With $1 \mathrm{~L}$ of primer, the silver ink penetrated completely inside the membrane and no conductivity was achieved. In the other cases; $2 \mathrm{~L}, 3 \mathrm{~L}$ and $4 \mathrm{~L}$ of silver, a well-defined square could be obtained with sheet resistance values below $1 \Omega \cdot \square^{-1}$ after a sintering process of $130{ }^{\circ} \mathrm{C}$ for $40 \mathrm{~min}$, showing the proper sealing function of the primer layer.

In the case of gold, similar results were obtained and 2 printed layers (2L) of primer ink were enough to form a smooth printed layer with a sheet resistance of $<2 \Omega \cdot \square^{-1}$ after a sintering process of $130{ }^{\circ} \mathrm{C}$ for $40 \mathrm{~min}$. In order to optimize the material waste and time cost, 2 layers were selected for developing the primer. Fig. $2 c$ shows a cross-section of a layer of silver ink printed onto the selected $2 \mathrm{~L}$ of primer.

\section{Passivation strategy}



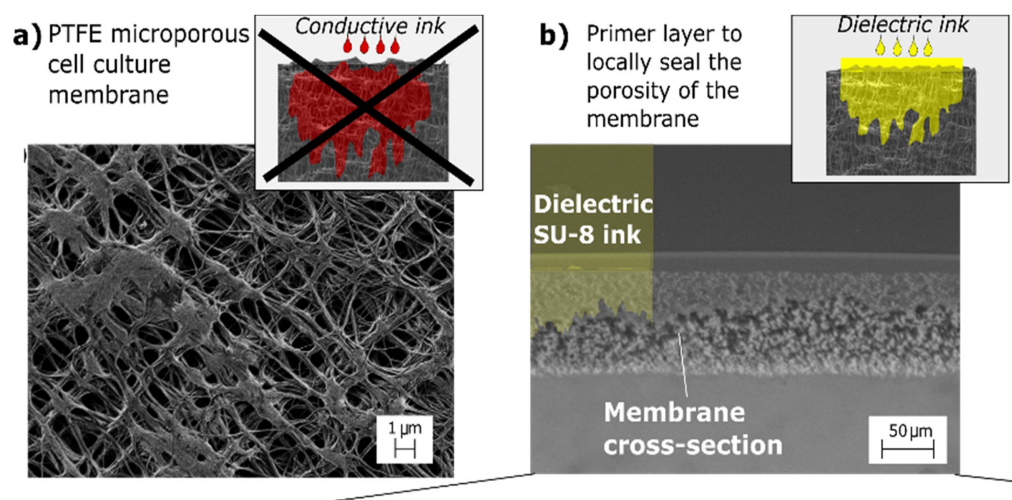
c) Conductive nanoparticle ink on the primer layer
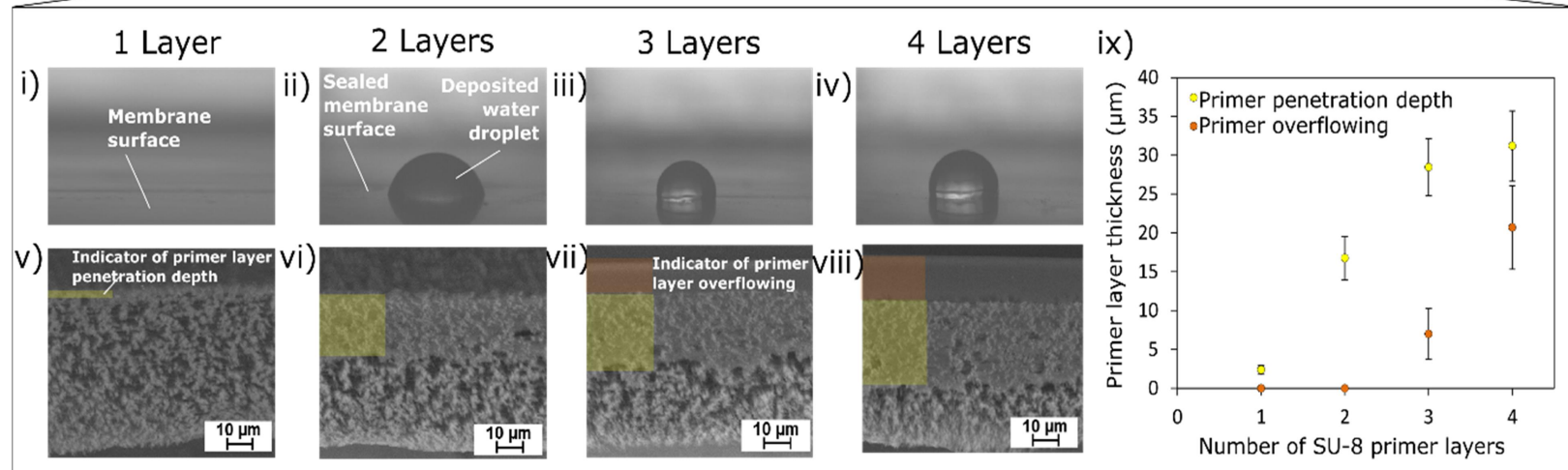

Fig. 2 a) SEM image of the PTFE porous membrane used to separate the inner compartments of the bioreactor, b) schematic of the strategy to block a porous substrate, using a primer layer locally sealing the porosity of the membrane, for the case of use one (1L), two (2L), three (3L) and four layers (4L); in (i-iv) is presented the sealing of a water drop on top of different numer of layers and in ( $\mathrm{v}$-viii) the cross section of the membrane with the SU-8 penetrated on it, and in ix) isrepresenting the thickness of the primer penetration depth inside the membrane and the primer overflowing above the membrane, c) cross-section of a conductive ink printed onto two primer layers.

The surface energy of the SU-8 printed layers was determined to be about $30.1 \mathrm{mN} \cdot \mathrm{m}^{-1}$ with a highly dispersed part of about $25.4 \mathrm{mN} \cdot \mathrm{m}^{-1}$ and a polar part of only $4.7 \mathrm{mN} \cdot \mathrm{m}^{-1}$ using the Owens, Wendt, Rabel, and Kaelble method. ${ }^{53}$ This surface energy normally has enough wettability for printing the conductive inks. However, the small polar part made it difficult to print the SU-8 insulator on top of the SU-8 primer layer, obtaining splitting droplets, as shown in Fig. S6a (ESI†). To improve the wettability of the SU-8 ink, an oxygen plasma treatment was performed ${ }^{54}$ to increase the amount of oxygen and carboxyl groups at the surface and, thus increase surface energy. ${ }^{55}$ The very gentle plasma conditions to change the affinity of the primer and the passivation layers were found as $24 \mathrm{~W}$ during $30 \mathrm{~s}$ with an oxygen gas pressure of 0.5 bar. With these plasma conditions, a change in the water contact angle from $89^{\circ}$ to only $32^{\circ}$ was achieved which in turn remarkably improved the layer formation, as shown in Fig. S6c-d (ESIt). The plasma treatment increased the wettability of the material, achieving surface energy values of about $37.3 \mathrm{mN} \cdot \mathrm{m}^{-1}$ with a reduction of the disperse part to about $21.8 \mathrm{mN} \cdot \mathrm{m}-1$ and a high increase in the polar part from $4.7 \mathrm{mN} \cdot \mathrm{m}^{-1}$ to 15.5 $\mathrm{mN} \cdot \mathrm{m}^{-1}$.

\section{Inkjet-printed sensors integration in the ExoLiver}

The same electrochemical three electrode system described in our previous work ${ }^{44}$ was used for the development of the DO sensors. In particular, sensors with a smaller WE diameter (300 $\mu \mathrm{m}$ ) were fabricated and tested in this work since the aim was to leave free the maximum area of membrane in order to maintain filtration.

From the point of view of the application, there were two requirements: i) to simultaneously monitor the oxygen at three points of the cell culture area: at the inflow (periportallike), at the middle and at the outflow (perivenous-like), to determine if an oxygen gradient along the chamber was present, and ii) to minimally modify and easily adapt the membrane to the Liver-On-a-Chip bioreactor.

Fig. 3a shows a schematic of the OOC system used in this work. After the printing of the three electrode structure of the DO sensors, an o-ring silicone based elastomeric gasket was attached to it, encompassing a cell culture area of $969 \mathrm{~mm}^{2}$ (34 $\mathrm{mm} \times 28.5 \mathrm{~mm}$ ). The detailed fabrication of the used bioreactor is described $\mathrm{in}^{43}$. Minimal changes were made to allow the connection of the sensors, the integration of an external $\mathrm{Ag} / \mathrm{AgCl} \mathrm{RE}$ and the commercial Clark-type oxygen sensor. These two external elements were incorporated at the top plate of the system to support the functionality and response of our developed sensors. Fig. 3b shows a crosssection of the bioreactor with the three printed sensors embedded in the porous membrane along the microfluidic channel and with the external RE and the Clark-type oxygen sensor. The sensors on the membrane were located facing the bottom channel, directly facing the seeded hepatocyte cell culture where the major oxygen concentration changes were expected to be measured. In particular, for the connection of the printed sensors to an external potentiostat, individual spring load connectors were incorporated in the top plate of 

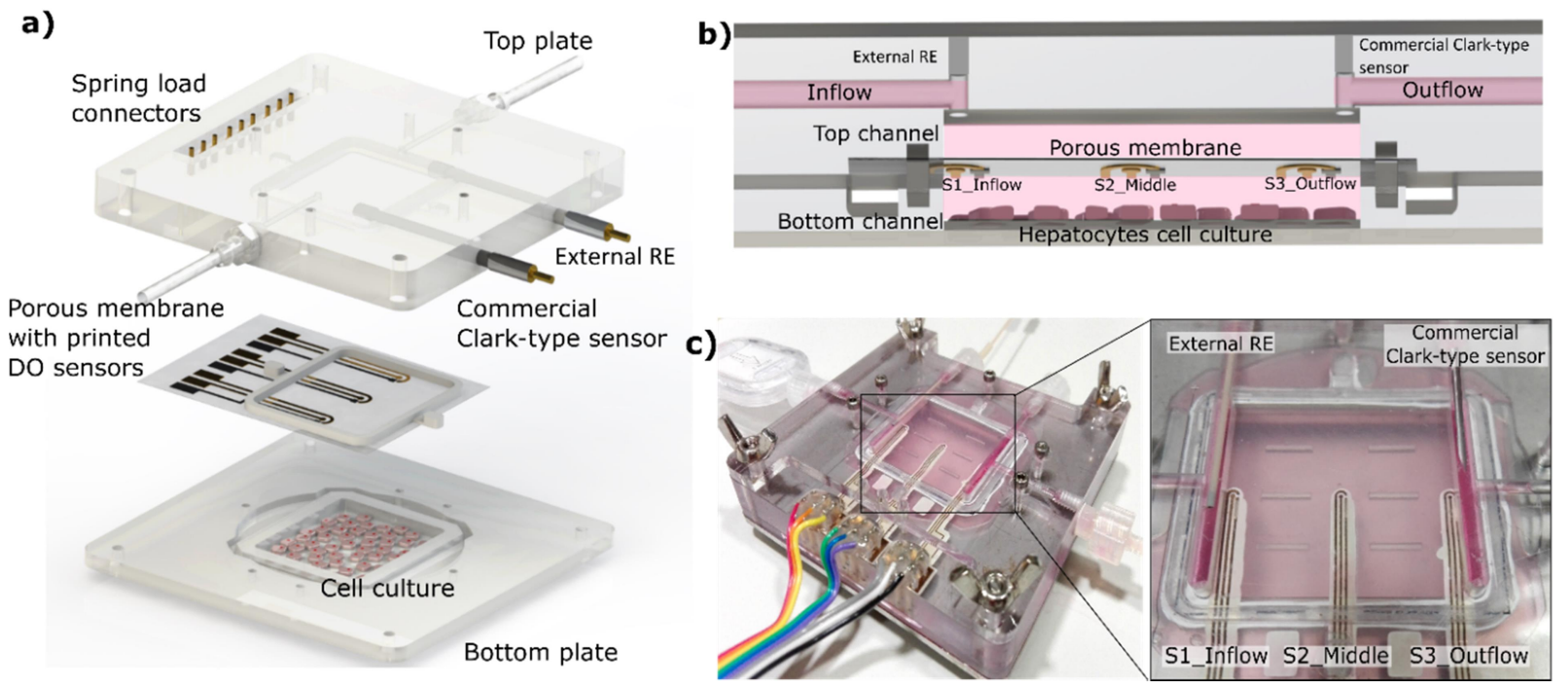

Fig. 3 Schematic of the OOC system with the modifications to incorporate the control with external elements and the spring load for the connectors on the top plate b) crosssection of the bioreactor showing the position of the three DO printed sensors, and c) real picture of the ExoLiver system with all the fluidic and electrical connections with the three printed sensors along the microfluidic channel and the external RE and Clark-type oxygen elements.

Fig. 3c, detailing the placement of the sensors.

\section{Sensor characterization and validation}

The sensors were electrochemically characterized in a similar way as described in our previous work. ${ }^{44}$ After the activation, electrode behaviour was studied by cyclic voltammetry in ferro/ferricyanide $(10 \mathrm{mM})$ solution, as shown in Fig. S7a (ESI + ). The anodic/cathodic peak current $\left(I_{p}\right)$ values determined were $I_{p}=1.2 \pm 0.2 \mu \mathrm{A}$ which are directly proportional to the WE area as described by the RandlesSěvčik equation. ${ }^{56}$ The measurement of oxygen is based on an oxygen reduction reaction at the $\mathrm{WE}$, which results in a detectable current. As the detection reaction implies oxygen consumption, the final interval time for measurement is a compromise between obtaining a real-time monitoring and not altering the cell culture medium. Oxygen concentration was measured with the three inkjet-printed sensors simultaneously every $15 \mathrm{~min}$. Each amperometric DO measurement took about $60 \mathrm{~s}$. The printed sensors with a diameter of $300 \mu \mathrm{m}$ had an oxygen consumption of about $2.94 \cdot 10^{-8} \mathrm{mgDO} \cdot \mathrm{s}^{-1}$ per sensor in each measurement. This consumption was sufficiently low compared with the DO consumption caused by the hepatocyte. According to the literature, the DO consumption for $10^{6}$ hepatocytes ranges from 0.96 to $2.88 \cdot 10^{-5} \mathrm{mgDO} \cdot \mathrm{s}^{-1}{ }^{57}$ Therefore, it can be considered that the viability of the cell culture remains unaltered. On the other hand, the DO consumption caused by the commercial Clark-type sensor was very low due to its small tip dimensions with about $4.1 \cdot 10^{-11} \mathrm{mgDO} \cdot \mathrm{s}^{-1}$. This together with its location on the top cover, where the medium was freshly maintained by the microfluidics, allowed continuous measurement each second.

The sensors were calibrated by polarization at $-650 \mathrm{mV}$. This value was found to be the optimal reduction potential interfering with the electro-active compound of the medium. The generation of electrons is proportional to the oxygen being reduced. Therefore, measurement of the generated current could be related to a concentration of oxygen in the sample. The linearity and sensibility of the sensors were verified in the calibrated medium (PBS) by bubbling a series of nitrogen/air gas mixtures. Fig. S7b (ESI + ) shows the calibration curves. In total, 28 platforms each with three fully-printed DO sensors were fabricated and calibrated. The sensors showed excellent linearity in the range of 0 to $9 \mathrm{mg} \cdot \mathrm{L}^{-1}$, with a sensitivity of $28 \pm 1 \mathrm{nA} \cdot \mathrm{L} \cdot \mathrm{mg}^{-1}$ and a correlation factor greater than 0.99 . The limit of detection was $0.11 \pm 0.02 \mathrm{mg} \cdot \mathrm{L}^{-1}$.

\section{DO monitoring inside the ExoLiver}

To assess the functionality of the printed sensors, two types of experiments were carried out. In the first, the ExoLiver system was assembled without primary cells (acellular ExoLiver) allowing the printed sensors to register the supply of oxygen to the culture media to serve as a control of the system (Fig. 4a). In the second type of experiment, the printed DO sensors were assembled in the ExoLiver after culturing the bottom plate with 1 million fresh primary hepatocytes isolated from healthy rats (Fig. 4b) and human (Fig. 4c) livers. We decided to perform the proof-of-concept studies in primary cells because they have a much higher applicability in the field than immortalized cell lines. Fig. 4 shows the measured results with a mean of $n=3$, and details of the DO concentrations in the three zones of the bioreactor. Additionally, oxygen was continuously measured with the commercial Clark-type sensor which was placed in the upper channel at the perivenous zone (outflow), due to the difficulty of integrating it in the lower channel without interfering with the cells.

In all experiments, the first three hours were set as the stabilization time required for the microfluidic system. During this period, the oxygen supply maintained the viability of the 
cell culture inside the Exoliver in both the upper and lower plate areas. These procedures ensured the long-term viability and functionality of the hepatocyte cell culture. After the stabilization period, FCCP $(0.5 \mu \mathrm{M})$ was added in 3 cumulative doses, dispensing a total of $129 \mu \mathrm{L}$ volume to the culture media reservoir to boost hepatocyte respiration. After the first addition, the system was set under anaerobic conditions by closing the medium reservoir to prevent oxygenation and DO concentrations were registered in real-time over the following 5 hours. FCCP has been described as an uncoupler of oxidative phosphorilation by promoting the disruption of the proton gradient across the mitochondrial membrane at concentrations as low as $1 \mu \mathrm{M}^{58}$ In order to balance the ATP supply with the cellular energy requirements, cells increase their oxygen-consuming rate to restore the proton gradient and overcome the dramatic decrease in intracellular ATP. Although this will be further discussed later, in our study the response of the hepatocytes for all replicates was observed to follow the same biological tendency, corroborating that FCCP provoked the increase of oxygen consumption and therefore a decrease in the DO concentration of the medium.

Reproducibility between the three independent experiments, shown in Fig. 4 as the grey shaded error bars, denotes the maximum deviation between experiments. During the whole time of the experiments with rat hepatocytes, DO maximum deviation was $\pm 0.4 \mathrm{mg} \cdot \mathrm{L}^{-1}(6 \%)$ in the acellular ExoLiver, $\pm 0.8 \mathrm{mg} \cdot \mathrm{L}^{-1}(9 \%)$ for rat hepatocytes and $\pm 1.5 \mathrm{mg} \cdot \mathrm{L}^{-1}$ (17\%) for human hepatocytes. These deviations might have been caused by 1 ) the oxygen conditions of the cell culture medium; 2) its oxygenation inside the incubator, or 3) differences in the seeding time, which could have provoked dedifferentiation of the primary hepatocytes thereby causing them to lose their liver-specific functions. In the case of the rat cells, intra-animal variability is another important factor, since primary cells isolated from different animals may differ in their metabolic response. In the case of the human cell experiments, higher variability can be undoubtedly explained due to basal differences in human liver donors.

As expected for the control experiments (acellular ExoLiver, Fig. 4a), the oxygen in the medium remained at optimal values without observing any change during the whole experiment, thus demonstrating that FCCP had no effect on the behaviour of the sensors. A slight decrease of the DO concentration could be observed at $\mathrm{t}=180 \mathrm{~min}$, corresponding to the opening of the incubator door for the FCCP addition; however it quickly recovered in the incubator conditions. As expected for the absence of cells, measurements of the three printed microelectrodes were of approximately the same DO concentration and no gradient of oxygen in the zoom image of Fig. 4a was observed in the lower plate. In addition, no substantial difference was noticed with the Clark-type sensor in the upper microfluidic channel.

\section{DO monitoring with rat hepatocyte ExoLiver}

In the rat hepatocyte ExoLiver (Fig. 4b), during the stabilization time, the cell media had enough nutrients to maintain both an adequate DO level and the viability of the cell culture inside the ExoLiver. In order to increase the respiratory activity of cells, FCCP was added as previously described and a final DO concentration of about $2.4 \pm 0.4 \mathrm{mg} \cdot \mathrm{L}^{-1}$ was detected at $\mathrm{t}=480$ $\mathrm{min}$ in the medium. Hepatocyte cellular viability was determined by observing polygonal shapes with angular edges. Fig. $4 \mathrm{~d}$ shows human hepatocyte cells, which are similar to the results obtained with rat cells. These images demonstrate the a) DO control without cells
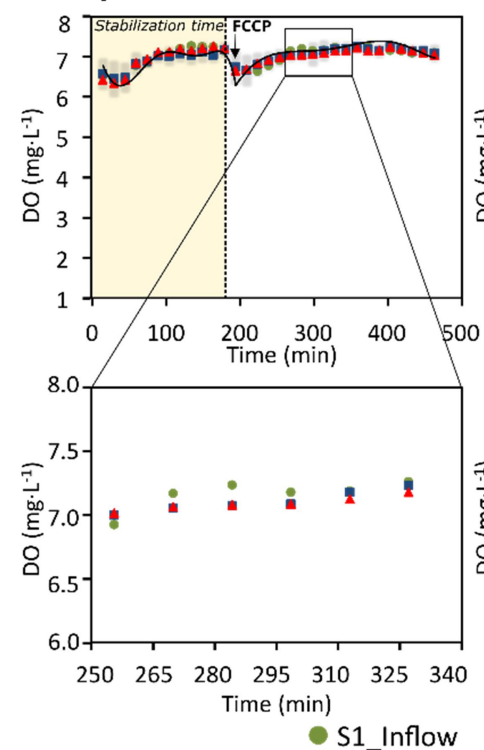

b) DO rat hepatocyte cells

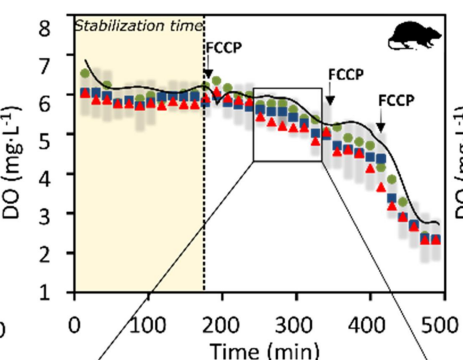

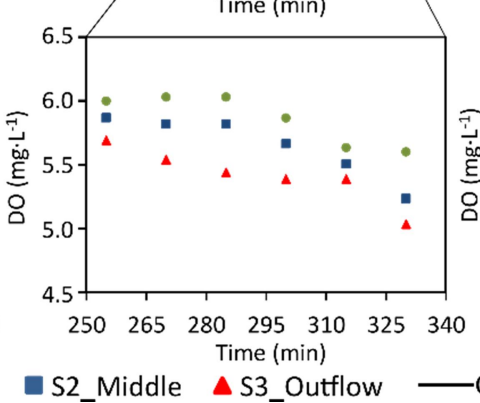

c) Do human hepatocyte cells

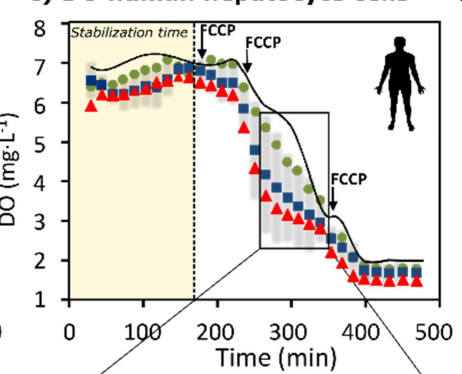

d)

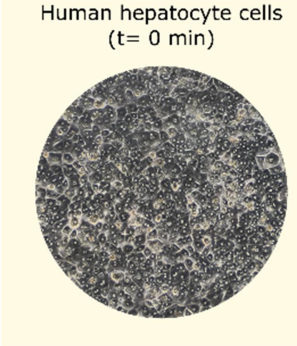

Human hepatocyte cells $(\mathrm{t}=480 \mathrm{~min})$
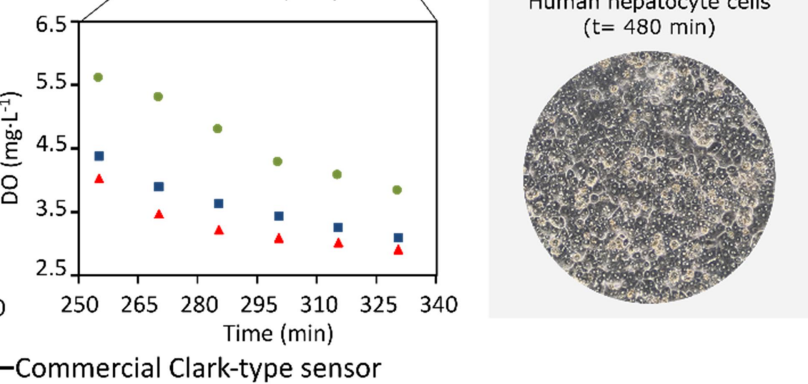

Fig. 4 DO monitored during 8 hours (green is the sensor placed in the inflow, blue $r$ the middle, red the outflow and black for the commercial DO Clark-type sensor with $n=3$ experiments (grey shaded is the bar error between experiments) in three cases, a) control without primary cells (acellular OOC) with a zoon in a section of the of the graph plotted for better readability of the different DO concentrations as a function of sensor position, b) with primary rat hepatocytes cell culture, and c) with primary human hepatocytes, with the addition of the FCCP drug after the 3 hours of stabilization, d) microscopic images of human hepatocytes cell culture at the begging (top) and at the end (bottom) of the experiment. 
high viability and unchanged morphology of the hepatocytes at the beginning and end of the experiment. The low DO concentration values found when the experiment had finished prompted us to consider an alternative mechanism by which the primary hepatocytes were obtaining ATP and cell death was prevented. We proposed that primary hepatocytes could be using anaerobic glycolisys in our experimental setting since this anaerobic metabolism is independent of oxygen and oxidative phosphorilation. Although anaerobic glycolisys is less efficient, it might have been sufficient to maintain the basal requirements of our cells for the short time they received FCCP treatment. Furthermore, this mechanism has been widely described as a biochemical feature of some tumor cells, which increase their cell energy production in the hypoxic microenvironment of the tumour. ${ }^{59,56}$

\section{Oxygen gradient}

The monitoring of changes in oxygen concentration in realtime allowed us to determine whether an oxygen gradient existed along the hepatocyte cell culture. To this end, different oxygen concentrations for rat hepatocyte cells were measured along the lower plate bioreactor as detailed in the zoom of Fig. $4 \mathrm{~b}$. Changes of up to $17.5 \%$ were measured between the inflow and the outflow. This gradient can be explained by the consumption of the cells along the lower plate of the bioreactor resulting in lower DO values at the outflow area of the system. We are confident that the metabolic activity of the hepatocytes along the sinusoid was mainly responsible for this oxygen gradient due to the fact that throughout the control experiment, no significant differences were observed in any of the three regions. In healthy liver tissue, the metabolic activity of hepatocytes along the sinusoid results in differences of about $50 \%$ between the periportal and the perivenous zones. ${ }^{53}$ The gradient differences found in our study between reality and the design underline the importance of oxygen monitoring for assessing an OOC device. This is particularly the case with liver tissue in which the oxygen gradient plays a strong regulatory role and is directly related to metabolic zonation, which is crucial for detoxifying xenobiotic metabolism.

\section{DO monitoring with human hepatocytes ExoLiver}

The same experimental approach was performed with primary human hepatocytes (Fig. 4c), which confirmed the results from rat hepatocytes. In this case, a higher oxygen gradient was observed of up to $32.5 \%$ between the inflow and the outflow. This gradient demonstrates that the reproducibility of the sinusoidal milieu of a human liver using primary human hepatocytes ${ }^{53}$ is more realistic than the obtained gradient with rat hepatocytes of a rat liver. Because zonation directly affects macronutrient metabolism, morphology and xenobiotic transformation in hepatocytes, the oxygen gradient found in our device could indeed have contributed to a better reproduction of the sinusoidal milieu and therefore to the maintenance of the hepatocytes. ${ }^{39}$ This is especially relevant both to properly reproduce hepatic microcirculatory characteristics (and therefore to mimic nature as much as possible), but also to allow the analysis of sub-populations of hepatic cells that have been cultured in vitro in a sinusoidal milieu under different concentrations of oxygen.

\section{Bioreactor system modelling for OCR estimation}

Oxygen consumption varies widely in different cell types and various methods of measuring the rate of oxygen consumption (OCR) are still a challenge in OOC systems, where dynamic and static fluidic conditions are combined in the bioreactor.

For the OCR analysis in our study, we proposed a one phase model developed to describe the complex ExoLiver reactor dynamics, which took into account the microfluidic and static channel separated by a membrane. It considered mineral solution recirculation through the upper channel and static flow within the bottom channel. The model included the mathematical expressions for the description of mass transport by adventive flow in the upper channel, mass transport through the upper and lower channel and diffusive mass transport within the lower channel. The theoretical model describing DO distribution was based on the mass balance along the ExoLiver reactor. Development of the mathematical model was based on the assumptions underlying consolidate models, ${ }^{61}$ as follows:

- Liquid phase recirculation regime in the axial direction was modelled considering plug flow. There was no radial velocity or axial dispersion.

- High permeable membrane and no mass transport resistance between upper and lower channel was considered.

Liquid phase static flow was considered within the lower channel.

- Diffusive mass transport within lower channel was described following Fick's law.

OCR is described using Michaelis-Menten kinetics. ${ }^{62}$

- Different maximum OCR's $\left(V_{\max }\right)$ were considered at different times related to the addition of FCCP and along the bottom channel.

Mass balance in the upper channel was expressed following Eq. (1),

$$
\frac{\partial D O}{\partial t}=v_{L} \cdot \frac{\partial D O}{\partial x}-D_{m} \cdot \frac{\partial^{2} D O}{\partial z^{2}},
$$

where $D O$ is the dissolved oxygen concentration in the upper channel $\left(\mathrm{mol} \cdot \mathrm{m}^{-3}\right), t$ is time $(\mathrm{s}), v_{L}$ is the axial liquid velocity $\left(\mathrm{m} \cdot \mathrm{s}^{-}\right.$ $\left.{ }^{1}\right), x$ is the axial direction $(\mathrm{m}), D_{m}$ is oxygen molecular diffusion coefficient $\left(\mathrm{m}^{2} \cdot \mathrm{s}^{-1}\right)$ and $z$ is the radial direction $(\mathrm{m})$.

Mass balance in the down channel is shown in the following equation:

$$
\frac{\partial D O}{\partial t}=D_{m} \cdot \frac{\partial^{2} D O}{\partial z^{2}}-V_{\max } \cdot \frac{D O}{K_{m}+D O},
$$

where $V_{\max }$ is the maximum OCR in the lower channel $(\mathrm{mol} \cdot \mathrm{m}$ $\left.{ }^{3} \cdot \mathrm{s}^{-1}\right)$ and $K_{m}$ is the affinity constant for DO $\left(\mathrm{mol} \cdot \mathrm{m}^{-3}\right)$. The resolution of the balance equations (Eq. (1) and Eq. (2)) that describe oxygen distribution along the ExoLiver reactor was done by a discretization procedure. The goal of the discretization was to simplify partial differential equations (depending on time $(t)$, axial direction $(x)$ and radial direction (z)) to ordinary differential equations (only depending on time $(t))$. With this aim, plug flow was divided into 3 sections, described as stirred tank reactors (with homogeneous properties). This division was carried out both in the upper and 
the lower channel. The results of the discretization are presented in Fig. 5a. The resulting set of ordinary equations was solved using MATLAB in a homemade modelling environment. A variable order method was used for solving stiff differential equations based on numerical differentiation formulas (NDFs). Selected model parameters were estimated during the calibration step by fitting the experimental DO concentrations to model predictions to describe the dynamics of the Exoliver reactor. The fitting method was based on seeking the minimum value of the objective function (Eq. (3)). This function was defined as the norm of the differences between the predicted DO concentrations by the mathematical model and the experimental data:

$$
F=\sqrt{\sum_{i=1}^{n}\left[y_{\text {exp }, i}-y_{\theta, i}\right]},
$$

where $F$ is the objective function to minimize, $n$ is the number of experimental measurements, $y_{\vartheta, i}$ is the simulated DO concentration $\left(\mathrm{mol} \cdot \mathrm{m}^{-3}\right)$ and $y_{\text {exp,i }}$ is the experimentally measured dissolved oxygen concentration $\left(\mathrm{mol} \cdot \mathrm{m}^{-3}\right)$. Qualitatively simulated profiles reproduced the experimental trend of DO along the lower channel throughout the monitoring (Fig. S8, ESIt). The quantitative comparison between the simulating the ExoLiver performance and the experimental DO profiles (obtained with microelectrodes) at the inflow, the middle and the outflow of the lower channel for rat and human cells monitoring is presented in Table S1 (ESIt).

Fig. $5 b$ shows the individual OCR values along the bottom channel estimated using the model previously described for rat and human cells. As basal respiration, OCR of hepatocyte

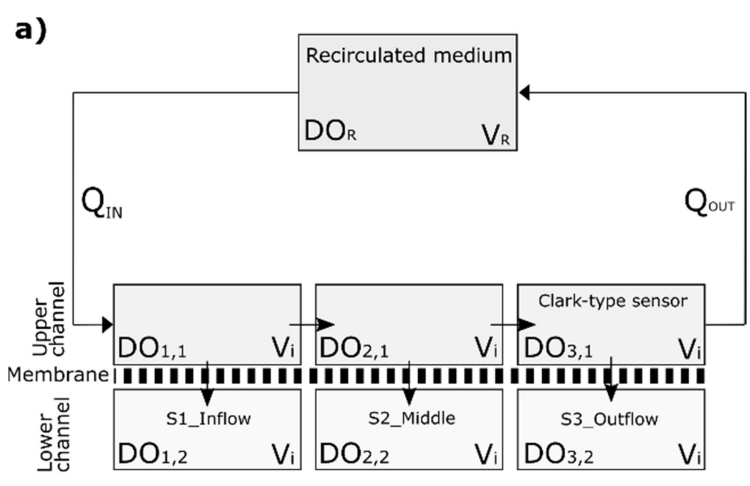

b)

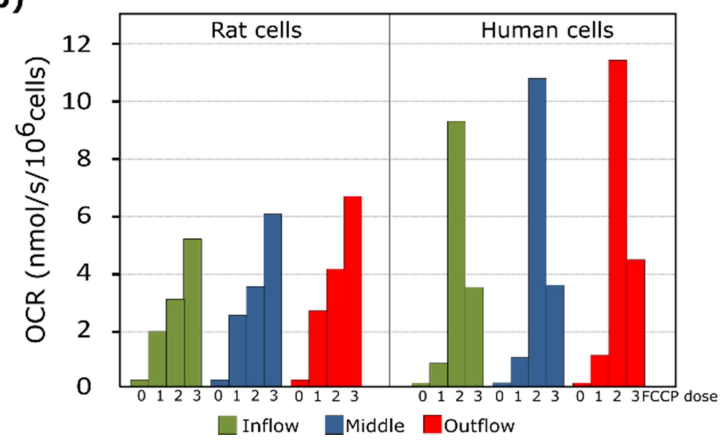

Fig. 5 a) The bioreactor modelling describing DO distribution based on the mass balance along the microfluidic and static channels separated by a membrane and divided in the three studied zones (inflow, middle and outflow). b) OCR estimation in the inflow, middle and outflow of the bioreactor bottom channel for the stabilization period and after the three FCCP additions for rat and human hepatocyte cells. of FCCP uncouples the mitochondria and increases oxygen consumption from the first dose of the drug by 10 times for rat cells and just 5 times for human cells. The sequential injection of FCCP affected the rat and human hepatocytes in different ways. For rat cells, each additional dose increased the OCR by $1.6 \pm 0.2$ times with respect the the previous dose, resulting in a mean OCR value of $2.33 \pm 0.28 \mathrm{nmol} / \mathrm{s} / 10^{6}$ cells after the first dose, $3.45 \pm 0.76 \mathrm{nmol} / \mathrm{s} / 10^{6}$ cells after the second dose and $5.95 \pm 0.67 \mathrm{nmol} / \mathrm{s} / 10^{6}$ cells after the third dose. However, for human hepatocytes, the higher effect was observed after the second dose of the drug, with an increase of up to $10.62 \pm 1.15$ $\mathrm{nmol} / \mathrm{s} / 10^{6}$ cells, and after the third dose, OCR recovered to a value of $3.98 \pm 0.29 \mathrm{nmol} / \mathrm{s} / 10^{6}$ cells. It can be observed that human cells were better able to support depolarization of the mitochondrial membrane potential after the first dose; however, once it was disrupted, the second dose caused a high level of oxygen depletion. The differential respiration behaviour observed for human cells after the first dose may also be explained as a result of the small interval time between the first and second dose: the interval induced an accumulative drug effect, and after the third dose, normal behaviour was restored.

Also, changes in the individual OCR values along the inflow, the middle and the outflow were observed. For both cell types, and for all FCCP additions, cell respiration was increased along the bottom channel. Cells seeded at the outflow zone presented a higher oxygen consumption with a mean increase of about $1.2 \pm 0.1$ times between the inflow and the outflow for rat cells, and $1.4 \pm 0.2$ times for human cells, respectively. As the oxygen gradient is depleted along the channel by oxygen cell respiration, cells of the inlet sector maintain a more aerobic metabolism, while cells of the middle and the outflow have already become used to having less oxygen and are more dependent on an anaerobic cell glycolysis.

In general, for all the experiments performed, the commercial Clark-type sensor data was in good agreement with the measurements of the printed sensors, thus validating the experiment. However, as can be seen in Fig. $4 \mathrm{~b}$ and c, a major advantage of our system is that it was able to measure the DO gradient, whereas the commercial sensor could not. This was due to the fact that measurement of the DO gradient requires an array of sensors in the lower channel where the oxygen changes occur in the immediate vicinity of the cell culture. ${ }^{65}$ In contrast, the commercial sensor was only able to take a single measurement at its location in the outflow of upper channel and could not measure oxygen consumption at the same time as changes occurred. Admittedly, this problem could be solved by inserting several sensors, notwithstanding the technological difficulties that this would imply and an increase in the final cost of the whole system. The fact that our DO printed sensors situated in the lower plate were able to detect changes before the commercial sensor situated in the upper plate emphasizes the physical limitations of commercial sensors and the high potential of inkjet-printed sensors As located on the membrane of a bioreactor. In addition, the size expected, and shape of DO printed sensors can be easily configured for the integration in any membrane, top or lower channel of any OOC presence system. 


\section{Conclusions}

We presented a novel approach for integrating sensors in an OOC system using IJP technology to allow in-situ measurements in real-time. Particularly advantageous was the possibility of integrating an array of DO sensors directly on a thin, flexible, delicate and porous cell culture membrane, which was used as a printing substrate. The strategy of locally sealing the porosity of the membrane using a biocompatible dielectric ink was studied, detailed and successfully applied on the membrane. The printed DO sensors were integrated in different locations of a previously described Liver-On-a-Chip system, exhibiting very good performance, with a linear response in a wide range of oxygen concentrations and with a low limit of detection. Its response was verified with a standard, commercially available Clark-type DO sensor. The functionality of our DO sensors was successfully demonstrated with primary rat and human hepatocyte cells cultivated in the lower plate. The location of the sensors at the inflow, middle and outflow zones of the bioreactor, allowed the measurement of an oxygen gradient up to $17.5 \%$ for rat cells and $32.5 \%$ for human cells. As the gradient of oxygen concentration is a phenomenon that is observed in almost all cell types and not only in hepatocytes and even in organs themselves, the results here obtained show that sensor responses are reliable for real-time monitoring of mitochondrial respiration at different areas of cell culture, paving the way for the use of this approach in any other OOC. The addition of several doses of FCCP provoked an increase in oxygen consumption up to $5.95 \pm 0.67 \mathrm{nmol} / \mathrm{s} / 10^{6}$ cells with respect to the control period for the experiment with rat cells and up to $10.62 \pm 1.15 \mathrm{nmol} / \mathrm{s} / 10^{6}$ cellsfor human cells. For rat hepatocytes it could be determined that OCR values at the outflow zone were $1.2 \pm 0.1$ times higher than in the inflow and $1.4 \pm 0.2$ times for human cells. Here it has been possible to demonstrate that cells at the inlet of the bioreactor maintain a more aerobic metabolism, while cells of the middle and the outflow have already become used to having less oxygen and are more dependent on an anaerobic cell glycolysis.

In summary, the results obtained in this work demonstrate that IJP is a feasible technique to integrated electrochemical sensors inside an OOC device for the online monitoring with minimal invasion, as they have a small footprint that can be arranged in arrays due to their low thickness and customizable size and shape. In addition, they allow a flexible, simple and seamless integration in different parts of the system, overcoming the higher cost and technological effort to include sensors inside OOC devices. The upgrade of OOC devices with printed sensors may open new research avenues where cells will be properly cultured and physiological measurements of different metabolic parameters, such as oxygen, $\mathrm{pH}$, glucose and lactate ${ }^{15,38}$ will be performed in real-time and close to the cells to obtain pericellular readings.

\section{Acknowledgements}

This work was supported by the Spanish government funded project DPI2015-65401-C3-3-R (MINECO/FEDER, EU), by the
Explora projects SAF2014-62114-EXP and BIO2014-61377-EXP and by a PIE-201450E116 funded by CSIC. We thank Emmanuel Stratakis from the Foundation for Research and Technology Hellas for his tests to seal the PTFE membranes with laser technology. We also thanks Ignacio Giménez from IACS (Universidad de Zaragoza) for their support in the analysis of the biological results. The authors also acknowledge ICTS "NANBIOSIS", more specifically by the SU-8 Unit of the CIBER in Bioengineering, Biomaterials \& Nanomedicine (CIBER-BBN) at the IMB-CNM (CSIC). This work has also made use of the Spanish ICTS Network MICRONANOFABS partially supported by MEINCOM. Part of this work was performed at the Centre Esther Koplowitz (CEK) - IDIBAPS, Barcelona.

\section{References}

1 G. H. Underhill, G. Peter, C. S. Chen and S. N. Bhatia, Annu. Rev. Cell Dev. Biol., 2012, 28, 385-410.

2 M. Mehling and S. Tay, Curr. Opin. Biotechnol., 2014, 25, 95102.

3 E. W. Esch, A. Bahinski and D. Huh, Nat. Rev. Drug Discov., 2015, 14, 248-260.

4 H. Kimura, T. Yamamoto, H. Sakai, Y. Sakai and T. Fujii, Lab. Chip, 2008, 8, 741-746.

5 H. J. Kim, D. Huh, G. Hamilton and D. E. Ingber, Lab. Chip, 2012, 12, 2165-2174.

6 M.-H. Wu, S.-B. Huang and G.-B. Lee, Lab. Chip, 2010, 10, 939.

7 D. Huh, G. A. Hamilton and D. E. Ingber, Trends Cell Biol., 2011, 21, 745.

8 L. Kim, Y.-C. Toh, J. Voldman and H. Yu, Lab. Chip, 2007, 7, 681694.

9 S. N. Bhatia and D. E. Ingber, Nat. Biotechnol., 2014, 32, 760772.

10 U. Marx, T. B. Andersson, A. Bahinski, M. Beilmann, S. Beken, F. R. Cassee, M. Cirit, M. Daneshian, S. Fitzpatrick, O. Frey, C. Gaertner, C. Giese, L. Griffith, T. Hartung, M. B. Heringa, J. Hoeng, W. H. de Jong, H. Kojima, J. Kuehnl, A. Luch, I. Maschmeyer, D. Sakharov, A. J. A. M. Sips, T. Steger-Hartmann, D. A. Tagle, A. Tonevitsky, T. Tralau, S. Tsyb, A. van de Stolpe, R. Vandebriel, P. Vulto, J. Wang, J. Wiest, M. Rodenburg and A. Roth, ALTEX, 2016, 33, 272-321.

11 S. J. Morgan, C. S. Elangbam, S. Berens, E. Janovitz, A. Vitsky, T. Zabka and L. Conour, Toxicol. Pathol., 2013, 41, 508-518.

12 M. Vinci, S. Gowan, F. Boxall, L. Patterson, M. Zimmermann, W. Court, C. Lomas, M. Mendiola, D. Hardisson and S. A. Eccles, BMC Biol., 2012, 10, 29.

13 L.-T. Cheah, Y.-H. Dou, A.-M. L. Seymour, C. E. Dyer, S. J. Haswell, J. D. Wadhawan and J. Greenman, Lab. Chip, 2010, 10, 2720-2726.

14 A. Escarpa and M. A. López, in Environmental Analysis by Electrochemical Sensors and Biosensors, eds. L. M. Moretto and K. Kalcher, Springer New York, 2014, pp. 615-650.

15 A. Weltin, K. Slotwinski, J. Kieninger, I. Moser, G. Jobst, M. Wego, R. Ehret and G. A. Urban, Lab Chip, 2014, 14, 138-146.

16 J. Kieninger, A. Weltin, H. Flamm and G. A. Urban, Lab. Chip, 2018, 18, 1274-1291.

17 C. Probst, S. Schneider and P. Loskill, Curr. Opin. Biomed. Eng., 2018, 6, 33-41.

18 J. Rogal, C. Probst and P. Loskill, Future Sci. OA, 2017, 3, Art. FSO180, 12. 
19 P. E. Oomen, M. D. Skolimowski and E. Verpoorte, Lab. Chip 2016, 16, 3394-3414.

20 M. D. Brennan, M. L. Rexius-Hall, L. J. Elgass and D. T. Eddington, Lab. Chip, 2014, 14, 4305-4318.

21 A. Polini, L. Prodanov, N. S. Bhise, V. Manoharan, M. R. Dokmeci and A. Khademhosseini, Expert Opin. Drug Discov., 2014, 9, 335-352.

22 F. Weise, U. Fernekorn, J. Hampl, M. Klett and A. Schober, Biotechnol. Bioeng., 2013, 110, 2504-2512.

23 Y. S. Zhang, J. Aleman, S. R. Shin, T. Kilic, D. Kim, S. A. Mousavi Shaegh, S. Massa, R. Riahi, S. Chae, N. Hu, H. Avci, W. Zhang, A. Silvestri, A. Sanati Nezhad, A. Manbohi, F. De Ferrari, A. Polini, G. Calzone, N. Shaikh, P. Alerasool, E. Budina, J. Kang, N. Bhise, J. Ribas, A. Pourmand, A. Skardal, T. Shupe, C. E. Bishop, M. R. Dokmeci, A. Atala and A. Khademhosseini, Proc. Natl. Acad. Sci. U. S. A., 2017, 114, E2293-E2302.

24 J. P. Wikswo, F. E. Block, D. E. Cliffel, C. R. Goodwin, C. C. Marasco, D. A. Markov, D. L. McLean, J. A. McLean, J. R. McKenzie, R. S. Reiserer, P. C. Samson, D. K. Schaffer, K. T. Seale and S. D. Sherrod, IEEE Trans. Biomed. Eng., 2013, 60, 682-690.

25 K. Rennert, S. Steinborn, M. Gröger, B. Ungerböck, A.-M. Jank, J. Ehgartner, S. Nietzsche, J. Dinger, M. Kiehntopf, H. Funke, F. T. Peters, A. Lupp, C. Gärtner, T. Mayr, M. Bauer, O. Huber and A. S. Mosig, Biomaterials, 2015, 71, 119-131.

26 A. Moya, X. Illa, I. Gimenez, Y. Lazo-Fernandez, R. Villa, A Errachid and G. Gabriel, Sens. Actuators B Chem., 2018, 255, 2861-2870.

27 R. Riahi, S. A. M. Shaegh, M. Ghaderi, Y. S. Zhang, S. R. Shin, J. Aleman, S. Massa, D. Kim, M. R. Dokmeci and A. Khademhosseini, Sci. Rep., 2016, 6, 24598.

28 P. Shah, J. V. Fritz, E. Glaab, M. S. Desai, K. Greenhalgh, A. Frachet, M. Niegowska, M. Estes, C. Jäger, C. Seguin-Devaux, F. Zenhausern and P. Wilmes, Nat. Commun., 2016, 7, 11535.

29 K. Domansky, W. Inman, J. Serdy, A. Dash, M. H. M. Lim and L. G. Griffith, Lab. Chip, 2010, 10, 51-58.

30 J. R. McKenzie, A. C. Cognata, A. N. Davis, J. P. Wikswo and D. E. Cliffel, Anal. Chem., 2015, 87, 7857-7864.

31 V. F. Curto, B. Marchiori, A. Hama, A.-M. Pappa, M. P. Ferro, M. Braendlein, J. Rivnay, M. Fiocchi, G. G. Malliaras, M. Ramuz and R. M. Owens, Microsyst. Nanoeng., 2017, 3, 17028.

32 O. Y. F. Henry, R. Villenave, M. J. Cronce, W. D. Leineweber, M. A. Benz and D. E. Ingber, Lab. Chip, 2017, 17, 2264-2271.

33 B. M. Maoz, A. Herland, O. Y. F. Henry, W. D. Leineweber, M. Yadid, J. Doyle, R. Mannix, V. J. Kujala, E. A. FitzGerald, K. K. Parker and D. E. Ingber, Lab. Chip, 2017, 17, 2294-2302.

34 J. U. Lind, T. A. Busbee, A. D. Valentine, F. S. Pasqualini, H. Yuan, M. Yadid, S.-J. Park, A. Kotikian, A. P. Nesmith, P. H. Campbell, J. J. Vlassak, J. A. Lewis and K. K. Parker, Nat. Mater., 2017, 16, 303-308.

35 P. Gruber, M. P. C. Marques, N. Szita and T. Mayr, Lab. Chip, 2017, 17, 2693-2712.

36 C.-C. Wu, H.-N. Luk, Y.-T. T. Lin and C.-Y. Yuan, Talanta, 2010, 81, 228-234.

37 E. E. Krommenhoek, M. van Leeuwen, H. Gardeniers, W. M. van Gulik, A. van den Berg, X. Li, M. Ottens, L. A. M. van der Wielen and J. J. Heijnen, Biotechnol. Bioeng., 2008, 99, 884-892.

38 S. E. Eklund, D. Taylor, E. Kozlov, A. Prokop and D. E. Cliffel, Anal. Chem., 2004, 76, 519-527.

39 T. Kietzmann, Redox Biol., 2017, 11, 622-630.

40 B. Bachmann, N. Y. Adly, J. Schnitker, A. Yakushenko, P. Rinklin, Andreas Offenhäusser and B. Wolfrum, Flex. Print. Electron., 2017, 2, 035003.

41 J. Wu, R. Wang, H. Yu, G. Li, K. Xu, N. C. Tien, R. C. Roberts and D. Li, Lab. Chip, 2015, 15, 690-695.
42 G. Jenkins, Y. Wang, Y. L. Xie, Q. Wu, W. Huang, L. Wang and X. Yang, Microfluid. Nanofluidics, 2015, 19, 251-261.

43 X. Illa, S. Vila, J. Yeste, C. Peralta, J. Gracia-Sancho and R. Villa, PLOS ONE, 2014, 9, e111864.

44 A. Moya, E. Sowade, F. J. del Campo, K. Y. Mitra, E. Ramon, R. Villa, R. R. Baumann and G. Gabriel, Org. Electron., 2016, 39, 168-176.

45 M.-S. To, E. C. Aromataris, J. Castro, M. L. Roberts, G. J. Barritt and G. Y. Rychkov, Arch. Biochem. Biophys., 2010, 495, 152158.

46 J. A. Heslop, C. Rowe, J. Walsh, R. Sison-Young, R. Jenkins, L. Kamalian, R. Kia, D. Hay, R. P. Jones, H. Z. Malik, S. Fenwick, A. E. Chadwick, J. Mills, N. R. Kitteringham, C. E. P. Goldring and B. Kevin Park, Arch. Toxicol., 2017, 91, 439-452.

47 E. Sowade, F. Göthel, R. Zichner and R. R. Baumann, Appl. Surf. Sci., 2015, 332, 500-506.

48 A. Denneulin, J. Bras, A. Blayo and C. Neuman, Appl. Surf. Sci., 2011, 257, 3645-3651.

49 L. M. Fischer, M. Tenje, A. R. Heiskanen, N. Masuda, J. Castillo, A. Bentien, J. Émneus, M. H. Jakobsen and A. Boisen, Microelectron. Eng., 2009, 86, 1282-1285.

50 V. A. Tarasova and V. N. Kiryushov, J. Anal. Chem., 2005, 60, 5660.

51 M. Vilaseca, H. García-Calderó, E. Lafoz, M. Ruart, C. I. LópezSanjurjo, M. P. Murphy, R. Deulofeu, J. Bosch, V. HernándezGea, J. Gracia-Sancho and J. C. García-Pagán, Liver Int., 2017, 37, 1002-1012.

52 F. J. del Campo, L. Abad, X. Illa, E. Prats-Alfonso, X. Borrisé, J. M. Cirera, H.-Y. Bai and Y.-C. Tsai, Sens. Actuators B Chem., 2014, 194, 86-95.

53 D. K. Owens and R. C. Wendt, J. Appl. Polym. Sci., 1969, 13, 1741-1747.

54 H. Y. Park, B. J. Kang, D. Lee and J. H. Oh, Thin Solid Films, 2013, 546, 162-166.

55 F. Walther, T. Drobek, A. M. Gigler, M. Hennemeyer, M. Kaiser, H. Herberg, T. Shimitsu, G. E. Morfill and R. W. Stark, Surf. Interface Anal., 2010, 42, 1735-1744.

56 A. J. Bard and L. R. Faulkner, Electrochemical methods: fundamentals and applications, Wiley, New York, 2001.

57 M. Shulman and Y. Nahmias, Methods Mol. Biol. Clifton NJ, 2013, 945, 287-302.

58 R. A. Haworth, A. Nicolaus, A. B. Goknur and H. A. Berkoff, J. Mol. Cell. Cardiol., 1988, 20, 837-846.

59 E. Bustamante and P. L. Pedersen, Proc. Natl. Acad. Sci. U. S. A., 1977, 74, 3735-3739.

60 T. Kietzmann and K. Jungermann, Cell Biol. Toxicol., 1997, 13, 243-255.

61 X. Guimerà, A. Moya, A. D. Dorado, R. Villa, D. Gabriel, G. Gabriel and X. Gamisans, Appl. Microbiol. Biotechnol., 2014, 99, 55-66.

62 P. Roy, H. Baskaran, A. W. Tilles, M. L. Yarmush and M. Toner, Ann. Biomed. Eng., 2001, 29, 947-955.

63 B. A. Wagner, S. Venkataraman and G. R. Buettner, Free Radic. Biol. Med., 2011, 51, 700-712.

64 B. D. Foy, A. Rotem, M. Toner, R. G. Tompkins and M. L. Yarmush, Cell Transplant., 1994, 3, 515-527.

65 E. W. K. Young and D. J. Beebe, Chem. Soc. Rev., 2010, 39, 10361048. 